\title{
Contrato eletrônico como cibercomunicação jurídica
}

Ricardo de Macedo Menna Barreto'1

\section{Resumo}

Este ensaio busca observar o comércio eletrônico, o ciberespaço e o contrato eletrônico a partir da Teoria dos Sistemas Sociais de Niklas Luhmann. Os sistemas sociais são compostos por comunicações, que são elementos característicos deste tipo de sistemas. Não obstante, partindo da noção de cibersistemas, podese falar em "cibercomunicação" (Stockinger). Destarte, o contrato eletrônico será observado como cibercomunicação jurídica. O contrato é uma forma privilegiada de comunicação, permitindo o acoplamento estrutural entre sistemas sociais e cibersistemas. Nessa dinâmica virtual, o sistema social, o sistema jurídico e o ciberespaço se erigem numa relação de interdependência mútua. Observar o contrato sistemicamente pode indicar diferentes possibilidades para a tomada de decisões no campo da dogmática contratual.

Palavras-chave: Contratos. Comércio eletrônico. Teoria dos sistemas. Comunicação. Direito.

\section{Introdução}

O presente trabalho tem por escopo observar sistemicamente o contrato eletrônico. Possibilitada pelo ciberespaço, a contratação eletrônica surge como uma das características mais marcantes do comércio eletrônico (e-commerce), retratando bem a realidade contemporânea do Direito, a saber, uma realidade comunicativa cada vez mais dominada pelo virtual.

${ }^{1}$ Graduando (formando) do $10^{\circ}$ semestre do Curso de Direito da UNISINOS/RS; Bolsista de Iniciação Científica CNPq/PIBIC, sob orientação do Professor Dr. Leonel Severo Rocha. Membro do Grupo de Pesquisa Teoria do Direito - CNPq; Membro do Projeto de Pesquisa Direito Reflexivo e Policontexturalidade que conta com o apoio do CNPq. Email: ricardomb@terra.com.br. 
Entendemos que essa figura contratual híbrida ainda encontra-se carente de uma observação diferenciada por parte dos juristas. Assim, na perspectiva deste trabalho, observaremos o contrato eletrônico a partir de uma (nova) categoria que denominamos “cibercomunicação jurídica”.

Note-se que a comunicação é um elemento característico de sistemas sociais. ${ }^{2}$ Não obstante, partindo da noção de cibersistemas, pode-se falar em uma comunicação no ciberespaço, isto é, em uma "cibercomunicação". ${ }^{3}$ O contrato eletrônico, nessa perspectiva, é uma forma diferenciada de comunicação, pois, graças a ele, sistemas virtuais podem acoplar-se ao processo de reprodução dos elementos compositores do sistema social, especificamente do sistema jurídico.

Partiremos inicialmente da análise dos aspectos que envolvem a Internet, o ciberespaço e a comunicação (1). A Internet possibilitou a virtualização do mundo em que vivemos, alargando a capacidade comunicativa da sociedade, criando um correlato virtual que se traduziu pela noção de ciberespaço. Este ciberespaço se caracteriza pelo universo das redes digitais, podendo ser considerado uma nova fronteira econômica e cultural, constituindo, ainda, um campo vasto, aberto, parcialmente indeterminado ${ }^{4}$, que necessita ser incorporado pela doutrina jurídica brasileira sob uma perspectiva diferenciada. A comunicação, por sua vez, é vista a partir da Teoria dos Sistemas de Niklas Luhmann, como um elemento característico de sistemas sociais. No entanto, a partir das contribuições de Gottfried Stockinger, essa noção de comunicação sofre algumas alterações substanciais. Tais alterações nos levarão direto àquilo que Stockinger denominou cibercomunicação.

Por conseguinte, teceremos algumas observações acerca do comércio eletrônico (2). O comércio eletrônico possui uma dinâmica que se caracteriza, principalmente, por comunicar além das fronteiras físicas. Hodiernamente é possível, em praticamente qualquer país, comprar produtos via Internet. Daí optamos por uma breve (porém necessária) análise dos aspectos legais desse tipo

\footnotetext{
${ }^{2}$ LUHMAN, N. Complejidad y modernidad: de la unidad a la diferencia. Edición e traducción de Josetxo Beriain y José María García Blanco. Madrid: Trotta, 1998.

${ }^{3}$ STOCKINGER, G. A interação entre cibersistemas e sistemas sociais. [S.l.], 2001. Disponível em: <www.bocc.ubi.pt>.

${ }^{4}$ LÉVY, Pierre. A inteligência coletiva: por uma antropologia do ciberespaço. São Paulo: Loyola, 2007. p. 104.
} 
de comércio. Destacaremos neste ponto algumas iniciativas legais da Colômbia; por conseguinte, alguns aspectos da Diretiva 2000/31/CE (União Europeia) e, derradeiramente, a Lei Modelo da UNCITRAL. Esta última se destaca por ser atualmente a iniciativa normativa mais ampla e de maior flexibilidade no que tange aos aspectos do comércio eletrônico

Derradeiramente, observaremos o contrato eletrônico como cibercomunicação jurídica (3). Tendo analisado na primeira parte deste ensaio aspectos atinentes à comunicação social, veremos nesta terceira parte como, a partir de uma noção de cibercomunicação, o contrato eletrônico pode ser explicado. Nessa perspectiva, o contrato eletrônico é visto como acoplamento estrutural, possibilitando a interação entre sistemas sociais e cibersistemas, sendo, portanto, uma figura híbrida.

O contrato eletrônico é fruto de uma realidade cada vez mais dominada pelo virtual. Observá-lo modernamente, a partir da união das ideias de Luhmann e de Stockinger, pode indicar diferentes possibilidades na construção de alternativas para a tomada de decisões no campo da dogmática contratual.

\section{Internet, ciberespaço e comunicação}

Após o surgimento da Internet e do ciberespaço, o computador fez com que as relações sociais se revestissem com configurações de notável complexidade. Nesse sentido, entendemos que o Direito não conseguiu acompanhar a evolução social no campo das tecnologias da informação, em especial no tocante aos novos meios de comunicação, como a Internet.

Por Internet entendemos aqui, conjuntamente com Dimaggio, "the electronic network of network that links people and information through computers and other digital devices allowing person-to-person communication and information retrieval". ${ }^{5}$ Note-se que a década de 90 foi decisiva para a popularização do uso da Internet, pois sua utilização massiva se iniciou exatamente naqueles

\footnotetext{
5 "A rede eletrônica de redes que liga as pessoas e a informação por meio de computadores e outros dispositivos digitais permitindo pessoa - a - pessoa a comunicação e o retorno de informação". DIMAGGIO, Paul et al. Social Implications of the Internet. Annual Review of Sociology, v. 27, 2001. Disponível em: <http://www.jstor.org/stable/2678624>. Acesso em: 21 jul. 2008.
} 
anos. Conforme Dizard, a rede vinha dobrando em tamanho a cada ano daquela década: só em 1995, por exemplo, a Web chegou a oferecer mais de "três milhões de páginas multimídia de informação e entretenimento, a maior parte gratuitamente". ${ }^{6}$

Hoje podemos afirmar que a Internet "virtualizou" o mundo, duplicando-o, ou seja, criando para ele um correlato imaterial, virtual, para tudo que há "fisicamente" em sociedade. Houve, com isso, uma amplificação da capacidade comunicativa da sociedade, gerando um espaço privilegiado de comunicação, que se denominou ciberespaço.

Ciberespaço, segundo Lévy, é "o espaço de comunicação aberto pela interconexão mundial dos computadores e das memórias dos computadores"? A principal consequência desse espaço virtual é o irrefreável fluxo comunicacional gerado pela crescente entrada de informações que ocorre diariamente na Internet. Com isso o virtual se inseriu em todos os campos da vida em sociedade; conforme Quéau, "cela s' accompagne d'une modification radicale de notre regard sur le monde, de notre manière d'envisager lês problèmes et de lês résoudre". ${ }^{8}$

O ciberespaço pode ser considerado não só um meio otimizador da comunicação, mas sim como uma forma de aumentar (ao mesmo tempo em que, paradoxalmente, reduz) a complexidade social. Nesse espaço virtual, a complexidade é sempre crescente, devido ao fato que "anyone can set up a web page, anyone can use (for minimal cost) electronic mail, and anyone can access information that may or may not the appropriation to all users". ${ }^{9}$ Cria-se, desse modo, uma estrutura que pode ser comparada a um verdadeiro sistema neurológico mundial, "una gigantesca rede de emisores

\footnotetext{
${ }^{6}$ DIZARD, Wilson P. A nova mídia: a comunicação de massa na era da informação. Rio de Janeiro: J. Zahar, 1998. p. 24.

${ }^{7}$ LÉVY, Pierre. Cibercultura. São Paulo: Ed. 34, 1999. p. 92.

${ }^{8}$ Isso se acompanha de uma modificação radical de nosso olhar sobre o mundo, de nossa maneira de encarar os problemas e de resolvê-los Tradução nossa. QUÉAU, Philippe. $C y$ berculture et info-éthique: relier les connaissances: le défi du XXI siècle. Paris: Éditions du Seuil, 1999. Journées thématiques conçues et animées par Edgar Morin, p. 371.

${ }^{9}$ Qualquer um pode criar uma página web, qualquer pessoa pode usar (por um custo mínimo) o correio eletrônico e qualquer pessoa pode acessar informações que podem ou não ser apropriadas por todos os usuários. Tradução nossa. GROSSBERG, Lawrence; WARTELLA, Ellen; WHITNEY, D. Charles. MediaMaking. Mass Media in a Popular Culture. Thousand Oaks: SAGE, 1998. p. 381.
} 
y receptores, que interactúan mediante agentes 'neurotransmisores' electrónicos - que permite al ser humano comunicarse en tiempo y espaço real, a semejanza do cérebro humano". 10

Daí podermos afirmar, sem receio de cairmos em exageros, que o ciberespaço é hoje um correlato virtual para praticamente tudo que se encontra ancorado no mundo físico, pois a partir dele, inserem-se neste mundo comunicativo: bancos, lojas, organizações, pontos/locais de encontro etc. Por isso, Lévy afirma que "le cyberspace nous permet d'observer de manière de plus en plus directe à peu près tout ce que nous voulons voir, et cette tendance est évidemment appelée à s'accélérer dans l'avenir". ${ }^{11}$ Ora, boa parte do comércio encontra-se hoje aportado em estruturas virtuais, facilitando em diversos aspectos a circulação de produtos os mais diversos. Produzem-se a partir daí operações que repercutem tanto no nível social como no ciberespacial. E nessa dinâmica entre o virtual e o material/físico, a sociedade se erige interdependente e comunicativamente. Do ponto de vista sistêmico, fala-se de uma sociedade composta de comunicações, na qual toda comunicação é uma operação interna à própria sociedade. Logo, surge a pergunta: poderia existir comunicação fora da sociedade?

Cabe destacar que, para Luhmann, a comunicação é o elemento básico da sociedade. Conforme esse autor, a comunicação é uma síntese entre informação, ato de comunicação e compreensão. ${ }^{12}$ Nesse sentido,

si la sociedad está constituida por la totalidad de todas las comunicaciones, el resto del mundo está condenado a permanecer sin palabra. Se retira al silencio; aunque ni siquiera éste es un concepto adecuado porque sólo puede permanecer en silencio quien pude comunicar. ${ }^{13}$

A comunicação, portanto, é um elemento característico de sistemas sociais. Estes se erigem e se articulam comunicativamente, e somente dessa maneira. Ora, a so-

${ }^{10}$ STEFFAN, Heinz Dieterich. Globalización, Educación y Democracia. In: CHOMSKY, N; STEFFAN, H. D. La aldea global. Taffala: Txalaparta, 1997. p.162.

${ }^{11} \mathrm{O}$ ciberespaço nos permite observar de maneira mais e mais direta para praticamente qualquer coisa que queremos ver, e essa tendência está evidentemente determinada a acelerar no futuro. Tradução nossa. LÉVY, Pierre. Cyberdémocratie. Paris: O. J. Janvier, 2002. p. 40.

${ }^{12}$ LUHMANN, Niklas. A improbabilidade da comunicação. Lisboa: Vega, 2001. p. 17.

${ }^{13}$ Idem. La sociedad de la sociedad. Tradução de Javier Torres Nafarrate. México: Herder; Universidad Iberoamericana, 2007. p. 119. 
ciedade "é o sistema abrangente de todas as comunicações, que se reproduz autopoieticamente, na medida em que produz, na rede de conexão recursiva de comunicações, sempre novas (e sempre outras) comunicações". ${ }^{14}$

No entanto, a partir das contribuições de Gottfried Stockinger, essa ideia de comunicação sofre algumas alterações substanciais. Ou seja, há uma (nova) diferenciação que pode (e precisa) ser feita, a saber, entre sistemas sociais e cibersistemas. ${ }^{15} \mathrm{Na}$ lógica da diferenciação sistema/ambiente empregada por Luhmann, significa afirmar que ambos (sistemas sociais e cibersistemas) são operativamente fechados, constituindo-se reciprocamente ambiente um do outro. Para ser mais preciso, Stockinger fala em "ciberambiente" toda vez que um cibersistema constituir ambiente de um sistema social. O ciberespaço, na perspectiva desse autor, pode ser conceituado como "ambiente de mídia que é formatado para receber determinados sistemas virtuais acionados por software" ${ }^{16}$ Sob essa ótica, a comunicação permanece, tal qual Luhmann, impessoal, ou seja, não se fala de sujeitos/indivíduos, pois “já não é o usuário que estabelece os limites e o horizonte da comunicação. É um sistema operacional eletrônico, em relação ao qual os usuários formam apenas o seu ambiente" ${ }^{17}$

Desse modo, sistemas sociais passam a criar uma relação de interação comunicativa com cibersistemas, criando-se uma relação de dependência, sendo que essa "dependência mútua também se reproduz e passa, assim, a fazer parte de cada sistema, através de interpenetração e acoplamento estrutural". ${ }^{18}$ É justamente em relação ao acoplamento desses distintos tipos de sistemas que trata este artigo.

${ }^{14}$ LUHMANN, Niklas. O conceito de sociedade. In: NEVES, Clarissa Eckert Baeta; SAMIOS, Eva Machado Barbosa. Novos desenvolvimentos na teoria dos sistemas. Niklas Luhmann: a nova teoria dos sistemas. Porto Alegre: UFRGS, 1997. p. 83.

${ }^{15}$ STOCKINGER, G. A interação entre cibersistemas e sistemas sociais. [S.1.], 2001. Disponível em: <www.bocc.ubi.pt>.

${ }^{16}$ Idem. Para uma teoria sociológica da comunicação. [S.1.], 2003. p. 127. Disponível em: $<$ www.bocc.ubi.pt $>$.

${ }^{17}$ Idem. A interação entre cibersistemas e sistemas sociais. [S.1.], 2001. Disponível em: <www. bocc.ubi.pt $>$.

${ }^{18}$ Idem. Para uma teoria sociológica da comunicação. [S.1.], 2003. p. 127. Disponível em: $<$ www.bocc.ubi.pt $>$. 
Partindo da proposta de Stockinger de observar sistemas virtuais como cibersistemas, pode-se falar igualmente em uma comunicação no ciberespaço, isto é, em uma "cibercomunicação". Significa afirmar que sistemas sociais utilizam para sua autopoiesis elementos e relações comunicativas operadas por cibersistemas, que passarão a ser parte integrante das ações e comunicações sociais. Entretanto, "a cibercomunicação multiplica e aumenta os desvios - as interpretações - de tal forma que se distanciam do significado original e criam áreas de sentido com seus significados próprios". ${ }^{19}$ Isso gera uma dificuldade ao sistema jurídico (visto como subsistema social) de observar este mundo virtual mesmo quando ele já se encontra acoplado àquele (daí a "cegueira dos operadores do Direito" no tocante a esses temas tecnológicos).

Neste trabalho, partiremos do entendimento de que tal acoplamento se dá por meio do contrato eletrônico. É este que, por sua vez, possibilita a estruturação do comércio eletrônico. Assim sendo, antes de observarmos esse tipo de contratação, adentraremos brevemente nos aspectos que envolvem o comércio eletrônico.

\section{Comércio eletrônico}

O comércio eletrônico (e-commerce) pode ser considerado um avanço em termos de abertura do mercado, uma vez que rompeu com limitações de espaço e tempo. Para Tellini, comércio eletrônico "seria toda a atividade que compreende intercâmbio eletrônico de dados. Vista sob esta ótica, a noção de comércio eletrônico compreende todos os contratos celebrados por meio eletrônico" ${ }^{20}$ Finkelstein, por sua vez, define comércio eletrônico como uma modalidade de compra a distância, consistente na aquisição de bens e/ou serviços, através de equipamentos eletrônicos. ${ }^{21}$

\footnotetext{
${ }^{19}$ STOCKINGER, G. Para uma teoria sociológica da comunicação. [S.1.], 2003. p. 131. Disponível em: <www.bocc.ubi.pt>.

20 TELLINI, Denise Estrella. Regime de direito internacional privado na responsabilidade dos provedores de internet: (Content Services Providers e Intermediary Service Providers) pela qualidade dos serviços executados online. Porto Alegre: S. A Fabris, 2006. p. 46.

${ }^{21}$ FINKELSTEIN, Maria E. Aspectos jurídicos do comércio eletrônico. Porto Alegre: Síntese, 2004. p. 53.
} 
Terminologia largamente utilizada pela doutrina estrangeira, que se incorporou à nacional ${ }^{22}$ para caracterizar esse tipo de relação jurídica comercial, são as expressões B2B e B2C. B2B significa Business to Business, isto é, refere-se especialmente aos contratos celebrados entre empresas. Já B2C (Business to Consumer), refere-se àqueles contratos celebrados entre fornecedores e consumidores.

Como vimos no ponto anterior, o ciberespaço propiciou a criação de um correlato virtual para praticamente toda atividade comercial que ocorre no mundo físico. Exemplificativamente, lojas antes só físicas se encontram igualmente na forma virtual. Entendemos que a vivência nesses dois mundos eleva demasiadamente a complexidade e a contingência social, criando riscos e abrindo a necessidade de estabelecermos relações de confiança ${ }^{23}$. O aumento desenfreado das possibilidades de compras virtuais é um dos principais responsáveis pelo incremento do risco no comércio eletrônico, além de que, conforme Yao-Hua Tan, "Electronic Commerce environment is obviously an environment with risk, simply because commerce in general involves risk". ${ }^{24}$

Não obstante, "this medium offers an unprecedented opportunity to increase the number of voices in the marketplace". ${ }^{25}$ Ora, criou-se, a partir do advento da Internet, uma facilidade de compra e um alcance ao público consumidor como nunca antes se teve na história. Produtos os mais diversos são hoje encontrados à venda no comércio eletrônico. Só para citar alguns, CDs, DVDs, livros e revistas encontram-se entre os produtos mais vendidos no comércio on-line brasileiro.$^{26}$

\footnotetext{
${ }^{22}$ Nesse sentido, ver, por todos: MARQUES, Cláudia L. Confiança no comércio eletrônico e a proteção do consumidor: um estudo dos negócios jurídicos de consumo no comércio eletrônico. São Paulo: Revista dos Tribunais, 2004.

${ }^{23} \mathrm{O}$ tema da confiança no comércio eletrônico a partir da matriz teórica pragmático-sistêmica já foi desenvolvido anteriormente em: MENNA BARRETO, Ricardo; ROCHA, Leonel Severo. Confiança nos Contratos Eletrônicos: uma Observação Sistêmica. Revista Jurídica Cesumar, Maringá , v. 7, n. 2, jul./dez. 2007.

${ }^{24}$ TAN, Yao-Hua; THOEN, Walter. Formal Aspects of a Generic Model of Trust for Electronic Commerce. In: PROCEEDINGS OF THE $33^{\mathrm{RD}}$ HAWAII INTERNATIONAL CONFERENCE ON SYSTEM SCIENCES. Annals... [S.l: s.n.], 2000.

${ }^{25}$ (Este meio oferece uma oportunidade sem precedentes para aumentar o número de vozes no mercado) Tradução livre. GROSSBERG, Lawrence; WARTELLA, Ellen; WHITNEY, D. Charles. MediaMaking. Mass Media in a Popular Culture. Thousand Oaks: SAGE, 1998. p. 381.

${ }^{26}$ Informação disponível em:< www.e-commerce.org.br>. Acesso em: 20 ago. 2008.
} 
Uma característica marcante desse tipo de comércio é a facilitação da circulação de informações atinentes à sua própria estruturação virtual. Tais informações circulam livremente no ciberespaço, tendo por finalidade otimizar a atividade comercial, gerando, por exemplo, o perfil dos consumidores. Conforme Rodotà, $\mathrm{o}$ elaborando le informazioni ottenute in occasione della fornitura dei servizi, possono creare informazione nuova (profili di consumo individuale o familiare, analisi di preferenze) che interessa altri soggetti, ai quali può essere venduta. ${ }^{27}$

Nesse mesmo sentido, não é mera coincidência recebermos e-mails $\left(\right.$ spams $\left.^{28}\right)$, divulgando produtos pelos quais nos interessamos, dias depois de os procurarmos/pesquisarmos na Internet. A navegação por certos sites faz com que fiquem registrados dados pessoais os mais diversos (traduzindo o perfil do consumidor). Para Sibilia

cada vez más, la identificación del consumidor pasa por su perfil: una serie de datos sobresu condición socioeconómica, sus hábitos y preferencias de consumo. Todas estas informaciones se acumulan mediante formularios de encuestas y se procesan digitalmente; luego se almacenan en bases de datos con acceso a través de redes, para ser consultadas, vendidas, compradas y utilizadas por las empresas en sus estrategias de marketing. De ese modo, el propio consumidor pasa a ser un producto en venta. ${ }^{29}$

${ }^{27} \mathrm{O}$ desenvolvimento da informação obtida durante a prestação de serviços pode criar novas informações (perfis de consumo individual ou familiar, a análise das preferências) que afetam outras entidades, as quais podem ser vendidas. RODOTÀ, Stefano. Tecnologie e diritti. Bologna: Il Mulino, 1995 p. 47.

${ }^{28}$ Spams são mensagens não solicitadas, contendo, na maioria das vezes, teor publicitário. Desvelando o sentido etimológico desta palavra, Steven Pinker afirma que Spam não é, "como acreditam alguns, uma sigla para 'Short, Pointless and Annoying Messages' (mensagens curtas, inúteis e irritantes). A palavra está, sim, relacionada ao nome do tipo de embutido vendido pela Hormel desde 1937, uma fusão de 'Spiced Ham' (presunto picante)". Um esquete do programa de televisão Flying Circus, do Grupo Monty Phyton (onde, em um café, "uma garçonete" (um integrante do grupo) atende um casal repetindo diversas vezes a palavra spam), inspirou hackers do final da década de 1980, que passaram a usá-la como verbo para inundar grupos de discussão com mensagens idênticas. In: PINKER, Steven. Do que é feito o pensamento: a língua como janela para a natureza humana. São Paulo: Companhia das Letras, 2008. p. 30-31.

${ }^{29}$ SIBILIA, Paula. El hombre postorgánico: cuerpo, subjetividad y tecnologías digitales. Buenos Aires: Fondo de Cultura Económica, 2005. p. 34-35. 
A virtualização, logo, é um fenômeno que atingiu em diversos pontos a atividade comercial. Isso até o ponto em que, conforme Lévy, "no comércio do futuro, a maior parte dos produtos serão concebidos e comprados pelos consumidores antes de serem efetivamente fabricados ou montados" ${ }^{30}$

Vale destacar ainda que a dinâmica desse tipo de comércio é, principalmente, a de comunicar além das fronteiras físicas. Atualmente é possível em praticamente qualquer país comprar produtos via Internet. Isso fez com que alguns países passassem a pensar no comércio virtual de forma diferenciada.

Para exemplificar, podemos trazer inicialmente o exemplo colombiano. A Colômbia, nos últimos anos, vem se estruturando gradativamente para acompanhar os avanços da era digital, tendo criado regulamentação (Lei n. 527 de 1999) para o Comércio Eletrônico. ${ }^{31}$ Esta lei $^{32}$ regulamenta o acesso e uso de mensagens de dados, do comércio eletrônico e das firmas digitais entre outros aspectos concernentes ao mundo virtual. A propósito, em seu artigo $2^{\circ}$, esta lei define comércio eletrônico como aquele comércio que

\begin{abstract}
Abarca las cuestiones suscitadas por toda relación de indole comercial, sea o no contractual, estructurada a partir de la utilización de uno o más mensajes de datos o de cualquier otro medio similar. Las relaciones de indole comercial comprenden, sin limitarse a ellas, las siguientes operaciones: toda operación comercial de suministro o intercambio de bienes o servicios; todo acuerdo de distribución; toda operación de representación o mandato comercial; todo tipo de operaciones financieras, bursátiles $y$ de seguros; de construcción de obras; de consultoría; de ingeniería; de concesión de licencias; todo acuerdo de concesión o explotación de un servicio público; de empresa conjunta y otras.
\end{abstract}

\footnotetext{
${ }^{30}$ LÉVY, Pierre. Filosofia World. O mercado. O ciberespaço A consciência. Lisboa: Piaget, 2001. p. 57. (Coleção Epistemologia e Sociedade).

${ }^{31}$ VILLAMIZAR, Francisco Reis. Comércio Eletrônico: recentes avanços jurídicos na Colômbia. In: SILVA JÚNIOR, Ronaldo Lemos da; WAISBERG, Ivo. (Org.). Comércio eletrônico. São Paulo: Revista dos Tribunais, 2001. p. 55-114.

${ }^{32}$ Para vê-la na íntegra, remeto ao site: http://www.secretariasenado.gov.co/ leyes/L0527_99. HTM.
} 
Há quem sustente que essa lei segue muito de perto a Lei Modelo da UNCITRAL. ${ }^{33}$ Carvajal, colocando as críticas que esta lei tem admitido, ainda completa afirmando que:

es claro que la nueva ley de comercio electrónico no es tecnológicamente neutra porque adopta como esquema de seguridad la Infraestructura de Clave Pública (Public Key Infrastructure). Esta tecnología está basada en la existencia de entidades certificadoras, legalmente facultadas para generar firmas digitales, sobre la base de un par de claves, una de conocimiento público y otra secreta.

Por outro lado, ainda no que tange às iniciativas legais acerca do comércio eletrônico, é oportuno mencionar a Diretiva n. 2000/31/CE ${ }^{34}$ do Parlamento Europeu e do Conselho, de 8 de junho de 2000, referente aos aspectos jurídicos dos serviços da sociedade da informação, notadamente o comércio eletrônico. A União Europeia, percebendo a necessidade de regulação dos mais diversos aspectos da denominada "Sociedade da Informação", criou a referida Diretiva, e segundo ela:

(2) o desenvolvimento do comércio electrônico na sociedade da informação faculta oportunidades importantes de emprego na Comunidade, particularmente nas pequenas e médias empresas, e irá estimular o crescimento econômico e o investimento na inovação por parte das empresas europeias e pode igualmente reforçar a competitividade da indústria europeia, contanto que a internet seja acessível a todos.

O principal objetivo dessa Diretiva é contribuir para o correto funcionamento do mercado interno, garantindo a livre circulação dos serviços da sociedade da informação entre Estados-Membros, conforme reza seu artigo $1^{\circ}$ (1). Em seu artigo $2^{\circ}$, a Diretiva delineia uma série de importantes conceitos, tais como: serviços da sociedade de informação, prestador de serviços, consumidor, comunicação comercial etc., de modo a elucidar quaisquer problemas hermenêuticos que venham a surgir.

Outro ponto que cabe mencionar da Diretiva 2000/31/CE é o que estabelece os contratos celebrados por meio eletrônico (Seção 3), que aqui muito nos

\footnotetext{
${ }^{33}$ CARVAJAL, Mauricio. Ley de Comercio Electrónico in Colombia (Ley 527 de 1999). AR: Revista de Derecho Informático. Disponível em: <http://www.alfa-redi.org/rdi-articulo. shtml?x=406>. Acesso em: 23 ago. 2008.

${ }^{34}$ Texto legal disponível integralmente no site da Comunidade Europeia, em diversas línguas, inclusive em português: www.europa.eu.int.
} 
interessa. Em seu artigo 9 (1), a Diretiva coloca que os Estados-Membros deverão assegurar que os seus sistemas legais permitam a celebração de contratos por meios eletrônicos. Isso impõe a necessidade de que o regime jurídico aplicável ao processo contratual "não crie obstáculos à utilização de contratos celebrados por meios eletrônicos, resultando na privação de efeitos legais ou de validade desses contratos, pelo fato de serem celebrados por meios eletrônicos”. Não obstante, existem exceções, pois conforme o artigo $9^{\circ}$ (2) existem contratos que, caso os Estados-Membros assim determinem, não se aplicarão ao artigo $9^{\circ}(1)$, entre eles os contratos que criem ou transfiram direitos sobre bens imóveis, contratos de caução etc.

Ainda, outro ponto igualmente importante dessa Diretiva é que, ao regular as atividades da sociedade de informação, ela não tratou de regras sobre competência judicial internacional - observe-se o artigo 1(4) - deixando, assim, os Estados-Membros livres para regularem sobre o tema. ${ }^{35}$

Por derradeiro, observemos a Lei Modelo da UNCITRAL ${ }^{36}$ (United Commission on International Trade Law) de 1996, sobre o Comércio Eletrônico. Essa Lei foi uma forma de buscar-se certa uniformidade no tocante a esse tipo de comércio. Podemos afirmar, sem sombra de dúvidas, que, pelo menos em termos normativos, a referida Lei Modelo é uma das grandes iniciativas que se teve nos últimos tempos - ressalva-se, uma iniciativa da ONU.

Ou seja, estamos diante de uma das principais referências sobre o tema, servindo de base para diversos regramentos que versam sobre o comércio eletrônico. Vários países serviram-se e vêm se servindo da Lei Modelo da UNCITRAL para estruturarem suas normas internas acerca desse tipo de comércio. Daí já se depreende a importância dessa lei. Contudo, destaque-se que essa Lei Modelo serve apenas de modelo (desculpem-nos a redundância) para países associados às Nações Unidas, sendo, portanto, uma sugestão para que os países associados elaborem leis tendo por base esse modelo. ${ }^{37}$

\footnotetext{
${ }^{35}$ TELLINI, Denise Estrella. Regime de direito internacional privado na responsabilidade dos provedores de internet: (Content Services Providers e Intermediary Service Providers) pela qualidade dos serviços executados online. Porto Alegre: S. A Fabris, 2006. p. 132.

${ }^{36}$ UNCITRAL. Comércio eletrônico. Disponível em:<http// www.uncitral.org $>$.

${ }^{37}$ FINKELSTEIN, Maria E. Aspectos jurídicos do comércio eletrônico. Porto Alegre: Síntese, 2004. p. 90.
} 
É provável que, atualmente, a iniciativa normativa mais clara e de maior flexibilidade no que tange ao comércio eletrônico seja a Lei Modelo da UNCITRAL. Seu caráter aberto permite a inclusão de novas formas virtuais de contratar que eventualmente ocorrem, e que podem gerar, por sua vez, novos modos de contratação num futuro próximo, diferentemente dos que conhecemos no momento presente.

Tendo visto aspectos gerais do comércio eletrônico, podemos passar para o ponto seguinte. Nele delinearemos um conceito sistêmico de contrato eletrônico, mais adequado com a realidade virtual que se impõe ao sistema jurídico atualmente.

\section{Contrato eletrônico como cibercomunicação jurídica}

O surgimento do ciberespaço e do comércio eletrônico fez com que as relações obrigacionais surgissem, por meio do contrato, revestidas com complexas configurações, uma vez que esse instituto teve suas estruturas modificadas no tocante à sua forma tradicional. Em outras palavras, o contrato apresenta-se distintamente quanto à sua forma física: encontra-se desmaterializado, virtual, resultante da utilização que se faz do computador atualmente para todas as etapas da contratação.

Aliás, esse cenário cibernético que se descortina ante o olhar horripilado dos juristas mais tradicionais não é nenhuma novidade, uma vez que há quase quatro décadas já se vislumbrava a possibilidade de o computador tornar-se parte efetiva da vida dos operadores do Direito. Nesse sentido, Tenório afirmou que "o computador interessa ao Direito. A cibernética não é assunto que pode ser ignorado. O Brasil precisa usar do que de mais moderno existe, para atravessar a barreira de seu crescimento".$^{38}$ Não há, portanto, nada de muito novo; o computador se inserir na vida dos juristas já era uma realidade que se cristalizava há praticamente 40 anos.

O contrato eletrônico é, no entanto, uma realidade relativamente recente. Sua utilização se acentuou no Brasil especialmente no final da década de 90 e no início dos anos 2000. Pois bem, para observarmos o contrato eletrônico, faremos

\footnotetext{
${ }^{38}$ TENÓRIO, Igor. Direito e cibernética. Brasília: Coordenada Editora de Brasília, 1970. p. 91.
} 
breves apontamentos sobre uma noção mais dogmática de contrato, construída recentemente pela doutrina brasileira. Só depois ponderaremos os aspectos sistêmicos dele, visando, assim, chegar à noção de cibercomunicação jurídica, peça-chave deste trabalho.

Note-se, primeiramente, que o contrato eletrônico é fruto de uma realidade cada vez mais dominada pelo virtual, operada notadamente pelo computador. Esse tipo de contratação tem por principal característica o emprego de um meio eletrônico para sua celebração, daí a expressão. ${ }^{39}$ Frise-se que falamos aqui de contratos eletrônicos em sentido amplo. Uma subespécie desse tipo de contrato, muito comum atualmente, seria o Contract Performed Online . ${ }^{40}$

Assim, um contrato eletrônico entre duas partes comunicantes, cuja execução da obrigação contratada se dê totalmente online e cujo objeto seja uma prestação de serviço eletrônica, será considerado eletrônico direto, vale dizer, um Contract Performed Online (CPO) ${ }^{41}$

Ante essa nova configuração contratual, a dogmática jurídica civilista/consumerista ainda não previu normativamente aquilo que se denominou contrato eletrônico. Não obstante, ests tipo de contrato já tem merecido uma (ainda tímida) atenção por parte da doutrina.

Newton de Lucca faz uma distinção, diferenciando contratos informáticos de telemáticos. $\mathrm{O}$ contrato eletrônico como entendemos neste trabalho, seria aquilo que o autor denomina contratos telemáticos, ou seja, aqueles "contratos que têm o computador e uma rede de comunicação como suportes básicos para sua celebração" ${ }^{42}$ Buscando explicar essa nova modalidade de contratação, Lorenzetti afirma que "uma vez constatado que o meio digital é utilizado para celebrar, cumprir ou executar um acordo, estaremos diante de um 'contrato eletrônico"' ${ }^{43}$

${ }^{39}$ FINKELSTEIN, Maria E. Aspectos jurídicos do comércio eletrônico. Porto Alegre: Síntese, 2004. p. 187.

${ }^{40} \mathrm{O}$ qual, por motivos de espaço, não abordaremos neste trabalho.

${ }^{41}$ TELLINI, Denise Estrella. Regime de direito internacional privado na responsabilidade dos provedores de internet: (Content Services Providers e Intermediary Service Providers) pela qualidade dos serviços executados online. Porto Alegre: S. A Fabris, 2006. p. 57.

${ }^{42}$ DE LUCCA, Newton. Aspectos jurídicos da contratação informática e telemática. São Paulo: Saraiva, 2003 p. 93.

${ }^{43}$ LORENZETTI, Ricardo L. Comércio eletrônico. São Paulo: Revista dos Tribunais, 2004 p. 287. 
Wielewicki, por sua vez, entende que os contratos eletrônicos podem ser definidos como "instrumentos obrigacionais de veiculação digital. São todas as espécies de signos eletrônicos transmitidos pela Internet que permitem a determinação de deveres e obrigações jurídicos". ${ }^{44}$

As observações desses autores convergem ao demonstrar claramente que o contrato, após o advento do computador, vem se despindo gradualmente da tradicional forma física com a qual é conhecido. As expectativas que as partes possuem agora são depositadas em um instrumento virtual (digital), por partes virtuais (!) propiciando, desse modo, construções jurídicas bem mais flexíveis.

Apreciados esses apontamentos doutrinários, podemos começar a observar sistemicamente o contrato. $\mathrm{O}$ contrato, luhmannianamente falando, pode ser definido, em um primeiro momento, como uma expectativa normativa ${ }^{45}$ que as partes possuem, ou seja, em frente a situações conflituosas complexas e contingentes, ele se mantém, traduzindo as vontades dos pólos contratantes. O contrato, como instituição, contribui "para a elevação do grau de abstração, da elasticidade, da capacidade de adaptação e da possibilidade de diferenciação de expectativas comportamentais institucionalizadas". ${ }^{46}$ É, nesse sentido, uma forma efetiva de evitarem-se previsões normativas para todo tipo de construções jurídicas que podem vir a surgir, sendo assim uma forma de traduzir normativa e flexivelmente expectativas comportamentais.

${ }^{44}$ WIELEWICK, L. Contratos e Internet: contornos de uma breve análise. In: SILVA JÚNIOR, Ronaldo Lemos; WAISBERG, Ivo (Org.). Comércio Eletrônico. São Paulo: Revista dos Tribunais, 2001 p. 198.

${ }^{45}$ Importante destacar que, para Niklas Luhmann, por expectativa entende-se o aspecto temporal do sentido na comunicação, e não apenas o estado atual de consciência de um indivíduo determinado. LUHMANN, Niklas. El derecho de la sociedad. Trad. Javier Torres Nafarrate. México: Universidad Iberoamericana, 2002. p. 182. Luhmann prevê, deste modo, duas possibilidades contrárias de reação a desapontamentos. Fala-se da diferenciação que esse sociólogo faz entre expectativas cognitivas / normativas. Tal diferenciação não é definida em termos semânticos ou pragmáticos, senão em termos funcionais. Em outras palavras, pode-se dizer que ela trabalha a antecipação tendo em vista a solução de um determinado problema. No que tange às expectativas cognitivas, há certa flexibilidade, existindo a possibilidade de alteração da expectativa. Ou mesmo, "ao nível cognitivo são experimentadas e tratadas expectativas que, no caso de desapontamentos, são adaptadas à realidade" LUHMANN, Niklas. Sociologia do direito I. Rio de Janeiro: Tempo Brasileiro, 1983. p. 56. No caso das expectativas normativas, ante o desapontamento, estas se sustentam. A frustração é algo até previsto, pois (sempre) existe a possibilidade de frustração; mas não se abandona a expectativa diante dela.

${ }^{46}$ Ibidem, p. 90. 
Por outro lado, podemos observar o contrato como acoplamento estrutural, entendendo o Direito e a Economia como sistemas autopoiéticos, isto é, como sistemas operativamente fechados, operando a partir de seus códigos (binários) próprios e de abertura cognitiva a irritações provenientes do ambiente. O contrato nessa ótica é, simultaneamente, uma operação jurídica e econômica. Sob esse aspecto, o contrato tem efeitos distintos não apenas nesses sistemas, mas igualmente em qualquer sistema parcial que se tome como ponto de observação. ${ }^{47}$ Porém, ainda precisamos elucidar a seguinte questão: o que é acoplamento estrutural?

Acoplamento estrutural é uma forma de explicar como é possível a comunicação entre diferentes sistemas. Conforme Luhmann, “el acoplamiento estructural es una forma, una forma constituida de dos lados; con otras palabras: una distinción" ${ }^{48} \mathrm{O}$ contrato, nessa perspectiva, é uma forma privilegiada de acoplamento estrutural, acoplando os sistemas do Direito e da Economia, que o reconstroem em seu interior como operações próprias do sistema. Considerado sob essa ótica, o contrato existe em ambos os sistemas.

O que se pretende demonstrar, no entanto, é que o contrato, nomeadamente o contrato eletrônico, acopla igualmente sistemas sociais e cibersistemas, sendo, portanto, uma figura híbrida. Como vimos acima, o contrato eletrônico é mediado por computadores, sendo estes, finalmente, os possibilitadores do avanço dessas tecnologias. Daí a importância de destacar, mesmo que brevemente, o computador na perspectiva da Teoria dos Sistemas de Luhmann.

Para Luhmann,

hoy día se usan computadoras cuyas operaciones no son accesibles ni a la conciencia ni a la comunicación; es decir, no son accesibles ni en la simultaneidad de tiempo ni en la reconstrucción. A pesar de ser máquinas producidas y programadas, tales computadoras trabajan

\footnotetext{
${ }^{47}$ ROCHA, Leonel Severo; DUTRA, Jéferson L. D. Notas Introdutórias à concepção sistemista de contrato. In: ROCHA, L. S.; STRECK, Lenio Luis; MORAIS, Jose L. Bolzan. Constituição, sistemas sociais e hermenêutica: programa de pós-graduação em Direito da UNISINOS: mestrado e doutorado. Porto Alegre: Livraria do Advogado; São Leopoldo: UNISINOS, 2005. p. 296.

${ }^{48}$ LUHMANN, Niklas. El derecho de la sociedad, Trad. Javier Torres Nafarrate. México: Universidad Iberoamericana, 2002. p. 508.
} 
de tal modo que para la conciencia y la comunicación resultan intransparentes. Son máquinas $[\ldots]$ invisibles. ${ }^{49}$

O que Luhmann quer dizer é que os computadores são máquinas que não possuem autonomia, ou seja, "vida própria”. São máquinas construídas e operadas por seres humanos. Do mesmo modo, suas operações internas não podem ser consideradas como comunicação, no sentido sistêmico luhmanniano do termo. Não obstante, Luhmann ainda entende que o computador seja capaz de proporcionar outras formas de acoplamento estrutural diferentemente das que já conhecemos. ${ }^{50}$ Pois essa é justamente a pista para cruzarmos o umbral que envolve o aspecto comunicacional da contratação eletrônica, e começarmos a adentrar no conceito de contrato eletrônico como cibercomunicação jurídica.

Como mencionamos anteriormente, a partir da proposta de Gottfried Stockinger, a noção de comunicação sofre algumas modificações. Não obstante, os pressupostos teóricos luhmannianos se adaptam sobremaneira à comunicação por meio do ciberespaço; ${ }^{51}$ partindo de tais pressupostos, observamos que sistemas sociais e cibersistemas são tidos como operativamente fechados, constituindo-se reciprocamente ambiente um do outro. Por operativamente fechados, definem-se os sistemas que, para sua produção, se remetem à rede de suas próprias operações e, nesse sentido, se reproduzem a si mesmos. ${ }^{52}$ Tratam-se, portanto, de sistemas autopoiéticos.$^{53}$

Estamos diante de um quadro no qual sistemas sociais (entre eles o Direito) passam a usar, para sua autopoiese, elementos e relações comunicativas (por exemplo, e-mails) operados por cibersistemas, os quais passam, a partir de então,

${ }^{49}$ LUHMANN, Niklas. La sociedad de la sociedad. Tradução de Javier Torres Nafarrate. México: Herder; Universidad Iberoamericana, 2007. p. 86.

${ }^{50}$ Ibidem p. 87.

${ }^{51}$ STOCKINGER, G. A interação entre cibersistemas e sistemas sociais. [S.1.], 2001. p. 2. Disponível em: <www.bocc.ubi.pt>.

${ }^{52}$ Idem. El derecho de la sociedad. Trad. Javier Torres Nafarrate. México: Universidad Iberoamericana, 2002. p. 98-100.

${ }^{53}$ Destaca-se que Niklas Luhmann foi fortemente influenciado pelos biólogos chilenos Humberto Maturana e Francisco Varela. MATURANA, H.; VARELA, F. El árbol del conocimiento: las bases biológicas del entendimiento humano. Buenos Aires: Lumen, 2003. Partindo dos contributos desses dois autores, Luhmann lança as bases de sua Teoria dos Sistemas Sociais Autopoiéticos em: LUHMANN, Niklas. Soziale systeme. grundisse einer allgemeinen theorie. Frankfurt: Suhrkamp Verlag, 1984. 
a ser parte integrante das ações e comunicações sociais. ${ }^{54} \mathrm{O}$ contrato eletrônico é justamente um desses elementos comunicativos, ou, mais que isso: é uma figura híbrida, ao mesmo tempo social e virtual, operando não só em sistemas sociais, mas igualmente em sistemas virtuais. É justamente por isso que "a velocidade da mudança social aumenta na medida em que o ciberespaço interage com o processo de comunicação social". ${ }^{55}$

O contrato eletrônico é, em verdade, uma forma diferenciada de comunicação. Nomeamos esse tipo de contrato de cibercomunicação jurídica. Ele possibilita que sistemas virtuais possam acoplar-se ao processo de reprodução dos elementos constitutivos do sistema social, especificamente do sistema jurídico. Nesse sentido, esse contrato é entendido como acoplamento estrutural.

Ora, se por um lado, o contrato acopla o sistema jurídico e o sistema econômico, por outro, ele igualmente acopla esses sistemas a cibersistemas. A complexa interação que daí advém gera irritações em ambos os sistemas. Tais irritações, por vezes, acabam por se traduzir (no caso do sistema do Direito) em problemas frente aos quais a dogmática jurídica (ainda) não encontrou solução. Não obstante, para Luhmann todo sistema necessariamente se adapta a seu ambiente, pois se não fosse dessa maneira não poderia existir.

Dentro do espaço de possibilidades disponíveis, realiza suas operações em condições de absoluta autonomia. $\mathrm{O}$ ambiente pode afetar o sistema somente quando produz irritações. A irritação é uma forma de percepção do próprio sistema. ${ }^{56}$

Não obstante, mesmo diante da dificuldade do sistema do Direito de traduzir essas irritações, observa-se que conjunta e reciprocamente há uma evolução de sistemas sociais e cibersistemas. O comércio e, consequentemente, o contrato eletrônico, retratam com acerto uma incorporação dessa realidade virtual pelo sistema social. Desse modo, “o acoplamento estrutural entre sistemas sociais e cibersistemas, formatados como ciberambientes para uso social,

\footnotetext{
${ }^{54}$ STOCKINGER, G. Para uma teoria sociológica da comunicação. [S.1.], 2003. p. 127. Disponível em: <www.bocc.ubi.pt>.

${ }^{55}$ Ibidem, p. 136.

${ }^{56}$ LUHMANN, Niklas. El derecho de la sociedad. Trad. Javier Torres Nafarrate. México: Universidad Iberoamericana, 2002. p. 510-511.
} 
passa a ser constitutivo para a gênese de ambos. Ele fortalece as relações entre os seus elementos" ${ }^{57}$

A Internet, nesse quadro sociovirtual, possui papel de destaque. Entendemos que é a grande rede que possibilita tais construções jurídico-sociais (virtuais), amplificando enormemente a capacidade comunicativa da sociedade. Ainda, conjuntamente com Stockinger, podemos observar que:

a internet ou rede não apenas amplifica a formação de campos de comunicação social enquanto "instrumentos": ela é capaz de fazer emergir construções culturais e sociais inéditas, que se transformam praticamente em sujeito, ganha "vida" própria, uma vida virtual equipada com inteligência artificial. ${ }^{58}$

Exatamente por isso não procede a tão famosa crítica (já clichê) de que a Internet criou um isolamento entre as pessoas ${ }^{59}$, pois graças a ela houve um alargamento da capacidade comunicativa da sociedade, repercutindo em todos os âmbitos do social, inclusive aproximando indivíduos de diferentes partes do globo.

Podemos, finalmente, observar que houve um aumento da complexidade social devido a este quadro virtual que se incorporou à sociedade. Criou-se aquilo que podemos denominar de complexidade ciberespacial, entendida como o correlato virtual de infinitas possibilidades criadas pelo ciberespaço para tudo o que existe em sociedade. Desse modo, nessa dinâmica entre o virtual e o material, a sociedade (sistema social), os subsistemas sociais (nomeadamente o Direito) e o ciberespaço se erigem comunicativamente numa relação de interdependência mútua, em um processo constante de redução e aumento de complexidade.

57 STOCKINGER, G. Para uma teoria sociológica da comunicação. [S.l.], 2003. p. 127. Disponível em: <www.bocc.ubi.pt $>$.

${ }^{58}$ Idem. A interação entre cibersistemas e sistemas sociais. [S.1.], 2001. p. 4-5. Disponível em: $<$ www.bocc.ubi.pt $>$.

${ }^{59}$ Sobre o impacto da Internet na interação entre os indivíduos, ver especialmente, DIMAGGIO, Paul et al. Social Implications of the Internet. Annual Review of Sociology, v. 27, 2001. Disponível em: <http://www.jstor.org/stable/2678624>. Acesso em: 21 jul. 2008. p. 314 et seq. 


\section{Considerações finais}

O contrato eletrônico, ainda carente de uma observação diferenciada por parte do Direito, foi observado neste trabalho como "cibercomunicação jurídica". Entendemos esse contrato como uma forma privilegiada que acopla não somente sistemas sociais (por exemplo, Direito e Economia), mas igualmente sistemas sociais com cibersistemas. O contrato eletrônico é, nesse sentido, uma figura híbrida.

Percebemos que nessa dinâmica entre o virtual e o material, a sociedade (vista como sistema social), os subsistemas sociais (nomeadamente o Direito) e o ciberespaço se erigem comunicativamente, numa relação de interdependência mútua. Essa dependência se reproduz, passando, assim, a fazer parte de cada sistema, isso por meio de interpenetração e acoplamento estrutural.

Destaca-se que o contrato eletrônico visto como cibercomunicação jurídica é uma forma de acoplamento estrutural, uma vez que, a partir dele, sistemas virtuais podem acoplar-se ao processo de reprodução dos elementos que compõe o sistema social, especificamente do sistema jurídico.

Procurou-se, portanto, no presente ensaio, observar o contrato eletrônico em consonância com as configurações de uma sociedade que podemos denominar complexa. A perspectiva esboçada neste trabalho é apenas uma das tantas formas possíveis de indicar possibilidades de construção de alternativas para a tomada de decisões no campo da dogmática contratual.

\section{Electronic contract as legal cibercommunication}

\section{Abstract}

This essay seeks to observe the e-commerce, cyberspace and the contract electronics from the Theory of Social Systems of Niklas Luhmann. Social systems are composed of communications, which are characteristic features of such systems. However, based on the concept of cibersystem, you can talk about "cibercommunication" (Stockinger). Thus, the electronic contract will be observed as legal cibercommunication. The contract is a form of privileged communication, allowing the structural coupling between social systems and cibersystems. This dynamic virtual, the social system, the legal system and cyberspace are building 
a relationship of mutual interdependence. Observe the contract system may give different possibilities for making decisions in the field of contractual dogmatic.

Keywords: Contracts. E-commerce. Theory of systems. Communication. Law.

\section{Referências}

BROWN, G. Spencer. Laws of form. New York: E. P. Dutton, 1979.

CARVAJAL, Mauricio. Ley de Comercio Electrónico in Colombia (Ley 527 de 1999). AR: Revista de Derecho Informático. Disponível em: <http://www.alfa-redi. org/rdi-articulo.shtml?x=406>. Acesso em: 23 ago. 2008.

DE LUCCA, Newton. Aspectos jurídicos da contratação informática e telemática. São Paulo: Saraiva, 2003.

DIMAGGIO, Paul et al. Social Implications of the Internet. Annual Review of Sociology, v. 27, 2001. Disponível em: <http://www.jstor.org/stable/2678624>. Acesso em: 21 jul. 2008.

DIZARD, Wilson P. A nova mídia: a comunicação de massa na era da informação. Rio de Janeiro: J. Zahar, 1998.

FINKELSTEIN, Maria E. Aspectos jurídicos do comércio eletrônico. Porto Alegre: Síntese, 2004.

GROSSBERG, Lawrence; WARTELLA, Ellen; WHITNEY, D. Charles. MediaMaking. Mass Media in a Popular Culture. Thousand Oaks: SAGE, 1998.

LÉVY, Pierre. A inteligência coletiva: por uma antropologia do ciberespaço. São Paulo: Loyola, 2007. . Cibercultura. São Paulo: Ed. 34, 1999.

. Cyberdémocratie. Paris: O. J. Janvier, 2002.

. Filosofia World. O mercado. O ciberespaço A consciência. Lisboa: Piaget, 2001. (Coleção Epistemologia e Sociedade).

LORENZETTI, Ricardo L. Comércio eletrônico. São Paulo: Revista dos Tribunais, 2004. 
LUHMANN, Niklas. A improbabilidade da comunicação. Lisboa: Vega, 2001.

- Complejidad y modernidad: de la unidad a la diferencia. Edición e traducción de Josetxo Beriain y José María García Blanco. Madrid: Trotta, 1998.

- El derecho de la sociedad. Trad. Javier Torres Nafarrate. México: Universidad Iberoamericana, 2002.

. La sociedad de la sociedad. Tradução de Javier Torres Nafarrate. México: Herder; Universidad Iberoamericana, 2007.

. O conceito de sociedade. In: NEVES, Clarissa Eckert Baeta; SAMIOS, Eva Machado Barbosa. Novos desenvolvimentos na teoria dos sistemas. Niklas Luhmann: a nova teoria dos sistemas. Porto Alegre: UFRGS, 1997.

. Sistemas sociales: lineamientos para una teoría general. Barcelona: Anthropos, 1998.

. Sociologia do direito I. Rio de Janeiro: Tempo Brasileiro, 1983.

- Soziale systeme. Grundisse einer allgemeinen theorie. Frankfurt: Suhrkamp Verlag, 1984.

MARQUES, Cláudia L. Confiança no comércio eletrônico e a proteção do consumidor: um estudo dos negócios jurídicos de consumo no comércio eletrônico. São Paulo: Revista dos Tribunais, 2004.

MATURANA, Humberto; VARELA, Francisco. El árbol del conocimiento: las bases biológicas del entendimiento humano. Buenos Aires: Lumen, 2003.

MENNA BARRETO, Ricardo; ROCHA, Leonel Severo. Confiança nos contratos eletrônicos: uma observação sistêmica. Revista Jurídica Cesumar, Maringá, v. 7, n. 2, jul./dez. 2007.

PINKER, Steven. Do que é feito o pensamento: a língua como janela para a natureza humana. São Paulo: Companhia das Letras, 2008.

QUÉAU, Philippe. Cyberculture et info-éthique: relier les connaissances: le défi du XXI siècle. Paris: Éditions du Seuil, 1999. Journées thématiques conçues et animées par Edgar Morin. 
ROCHA, Leonel Severo; DUTRA, Jéferson L. D. Notas Introdutórias à concepção sistemista de contrato. In: ROCHA, L. S.; STRECK, Lenio Luis; MORAIS, Jose L. Bolzan. Constituição, sistemas sociais e hermenêutica: programa de pós-graduação em Direito da UNISINOS: mestrado e doutorado. Porto Alegre: Livraria do Advogado; São Leopoldo: UNISINOS, 2005.

RODOTÀ, Stefano. Tecnologie e diritti. Bologna: Il Mulino, 1995.

SIBILIA, Paula. El hombre postorgánico: cuerpo, subjetividad y tecnologías digitales. Buenos Aires: Fondo de Cultura Económica, 2005.

STEFFAN, Heinz Dieterich. Globalización, Educación y Democracia. In: CHOMSKY, N; STEFFAN, H. D. La aldea global. Taffala: Txalaparta, 1997.

STOCKINGER, G. A interação entre cibersistemas e sistemas sociais. [S.1.], 2001. Disponível em: <www.bocc.ubi.pt $>$.

. Para uma teoria sociológica da comunicação. [S.1.], 2003. Disponível em: $<$ www.bocc.ubi.pt $>$.

TAN, Yao-Hua; THOEN, Walter. Formal Aspects of a Generic Model of Trust for Electronic Commerce. In: PROCEEDINGS OF THE 33 ${ }^{\mathrm{RD}}$ HAWAII INTERNATIONAL CONFERENCE ON SYSTEM SCIENCES. Annals... [S.l: s.n.], 2000.

TELLINI, Denise Estrella. Regime de direito internacional privado na responsabilidade dos provedores de internet: (Content Services Providers e Intermediary Service Providers) pela qualidade dos serviços executados online. Porto Alegre: S. A Fabris, 2006.

TENÓRIO, Igor. Direito e cibernética. Brasília: Coordenada Editora de Brasília, 1970.

VILLAMIZAR, Francisco Reis. Comércio Eletrônico: recentes avanços jurídicos na Colômbia. In: SILVA JÚNIOR, Ronaldo Lemos da; WAISBERG, Ivo. (Org.). Comércio eletrônico. São Paulo: Revista dos Tribunais, 2001.

WIELEWICK, L. Contratos e Internet: contornos de uma breve análise. In: SILVA JÚNIOR, Ronaldo Lemos; WAISBERG, Ivo (Org.). Comércio eletrônico. São Paulo: Revista dos Tribunais, 2001. 
